\title{
An inverse relationship between serum zinc and C-reactive protein levels in acutely ill elderly hospital patients
}

\author{
G.M. Craig, S.J. Evans and B.J. Brayshaw \\ Departments of Geriatric Medicine and Clinical Biochemistry, General Hospital, Northampton \\ $N N 15 B D, U K$
}

\begin{abstract}
Summary: Serum zinc and C-reactive protein (CRP) levels were measured in two groups of acutely ill geriatric hospital in-patients. Serum CRP levels were greater than $10 \mathrm{mg} / \mathrm{l}$ in $62 \%$ of the first group and $\mathbf{4 7 \%}$ of the second. There was a significant negative correlation between zinc and CRP in both groups $(r=-0.33, P<0.001, n=103)$ and $(r=-0.29, P<0.001, n=135$ respectively).

The serum CRP was raised in $30 \%$ of long stay patients $(n=50)$ and $23 \%$ of a control group of elderly hospital patients with a normal serum albumin $(n=71)$, but there was no correlation between zinc and CRP in these patient groups. The results indicate that an acute phase response influences serum zinc levels in acutely ill geriatric patients. There is reason to believe that a distinction should be made between true zinc deficiency and a low serum zinc secondary to acute zinc redistribution during an inflammatory response. Measurement of CRP may help to distinguish between these two situations. We advise that if the serum zinc is low and CRP is significantly raised, zinc supplements should be avoided and a source of infection should be sought. Following recovery from severe infection low serum zinc levels return to normal while elevated CRP levels fall.
\end{abstract}

\section{Introduction}

Earlier work led us to suspect that an acute phase response contributed to the low serum zinc levels observed in acutely ill geriatric patients. ${ }^{\prime}$ The present study confirms this suspicion. A raised C-reactive protein (CRP) is well established as a good indicator of an acute phase response ${ }^{2}$ and of infection in the elderly. ${ }^{3}$ It is also well established that hepatic uptake of zinc in response to interleukin I or a similar mediator, is associated with synthesis of alpha-2-acute phase reactant proteins such as CRP.,5

We therefore investigated the relationship between serum zinc and CRP levels in acutely ill and in long stay geriatric patients.

\section{Patients and methods}

In the initial study serum zinc and CRP levels were measured in 103 acutely ill patients admitted to acute geriatric wards, in 50 long stay geriatric patients and in a control group of 71 patients with normal serum albumin levels. These patients formed part of a larger series of elderly hospital

\footnotetext{
Correspondence: G.M. Craig, M.D., F.R.C.P., Department of Geriatric Medicine, St Edmund's Hospital, Northampton NN1 4DS, UK

Accepted: 12 July 1990
}

patients studied from November 1985 onwards in whom we measured serum zinc, total protein, albumin, alpha-2-macroglobulin and transferrin. Their serum zinc and protein levels have already been reported.

The 103 acutely ill patients in whom CRP was measured consisted of 58 women and $45 \mathrm{men}$, aged between 66 and 97 years. The long stay geriatric patients had all been in hospital for at least 3 months, and comprised 25 women and 25 men, aged between 61 and 100 years. The normal albumin control group of elderly patients were on general medical or surgical wards, or were attending outpatient clinics. All had normal serum levels of total protein, albumin, bilirubin and aspartate aminotransferase and urea levels of less than $10.5 \mathrm{mmol} / \mathrm{l}$. There were 50 women and $21 \mathrm{men}$ aged between 65 and 92 years.

The study was repeated in a second group of 135 acutely ill geriatric patients ( 90 women and 45 men) aged between 65 and 99 years admitted between April 1987 and February 1988.

Blood samples from the acutely ill geriatric patients were collected in the morning within a few days of admission. Serum zinc and CRP levels were measured on the same blood sample in each patient. Serum zinc was measured by atomic absorption spectrophotometry. Samples for CRP determination were stored frozen at $-20^{\circ} \mathrm{C}$ and were assayed using standard Mancini end point 
radial immunodiffusion techniques on commercial plates. The between batch imprecision of these methods measured as coefficients of variations were zinc $2.3 \%$ (at $13.4 \mu \mathrm{mol} / \mathrm{l}$ ) and $3.6 \%$ (at $12.6 \mu \mathrm{mol} / \mathrm{l}$ ) and CRP $3.1 \%$ (at $77 \mathrm{mg} / \mathrm{l}$ ).

Some relevant clinical information from acutely ill patients is mentioned. Acute and recovery phase blood samples were obtained in 6 patients with severe infections, and the results are reported.

\section{Results}

The mean serum zinc and CRP results in all patient groups are shown in Table I. A high proportion $(62 \%)$ of patients in the first acute group had a CRP level greater than $10 \mathrm{mg} / \mathrm{l}$ (the upper limit of the reference range), and there was a highly significant negative correlation between serum zinc and serum CRP results $(r=-0.33, P<0.001)$ (Figure 1). These results were confirmed in the second series of acutely ill patients although fewer of these $(47 \%)$ had a raised CRP; the correlation coefficient for zinc and CRP was $r=-0.292$, $P<0.001$. In contrast only $30 \%$ of the long stay patients and $23 \%$ of the normal albumin control group of patients had a raised CRP and there was no correlation between zinc and CRP in these groups.

Results in the acute group patients were also analysed by division of patients into subgroups according to their CRP level, so that subgroup A had CRP levels below $10 \mathrm{mg} / 1$ (normal levels), subgroup B CRP levels between 11 and $50 \mathrm{mg} / \mathrm{l}$, subgroup C CRP levels between 51 and $100 \mathrm{mg} / \mathrm{l}$ and subgroup D CRP levels above $101 \mathrm{mg} / 1$. Zinc results in these subgroups were compared by Student's $t$ test. In both series of acute patients studied the zinc results of subgroup A (normal CRP levels) were significantly higher than those in subgroup D (CRP levels above $101 \mathrm{mg} / \mathrm{l}$ ). In one series of acute patients zinc results in subgroup $A$ were significantly higher than those in subgroup $C$ (CRP 51-100 mg/l). Mean results with statistical

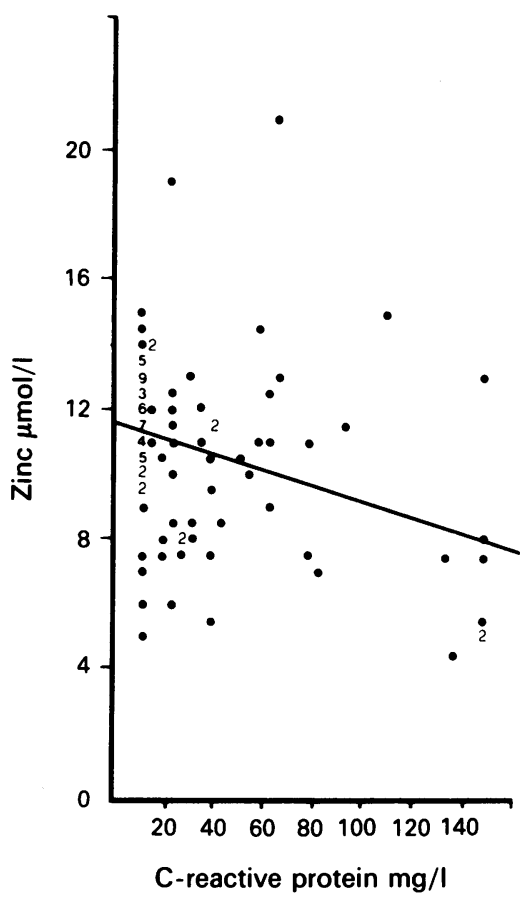

Figure 1 Negative correlation between serum zinc and CRP in acutely ill geriatric patients, $r=0.33(P<0.001)$.

significance are shown in Table II.

Acute and recovery phase changes in serum zinc and CRP were demonstrated in 6 patients with acute infections and the results are shown in Figure 2 . In each case the serum zinc rose to normal and the elevated CRP level fell with recovery.

\section{Discussion}

The causes of a low serum zinc are numerous. ${ }^{6}$ Serum zinc levels have been shown to fall during

Table I Serum zinc and CRP levels (mean \pm s.d.) with correlation coefficients for zinc and CRP in each patient group

\begin{tabular}{|c|c|c|c|c|c|}
\hline & $n$ & $\begin{array}{c}\text { Serum zinc } \\
\mu \mathrm{mol} / \mathrm{l}\end{array}$ & $\begin{array}{c}\text { Serum } \\
\mathrm{mg} / \mathrm{l}\end{array}$ & $r$ & $P$ \\
\hline Acute geriatric (1) & 103 & $10.7 \pm 2.81$ & $34 \pm 39.3$ & -0.33 & $<0.001$ \\
\hline Acute geriatric (2) & 135 & $11.9 \pm 3.01$ & $48 \pm 49.3$ & -0.292 & $<0.001$ \\
\hline Long stay geriatric & 50 & $9.5 \pm 1.92$ & $18 \pm 18.8$ & -0.166 & NS \\
\hline $\begin{array}{l}\text { Normal albumin controls } \\
\text { Reference range }\end{array}$ & 71 & $\begin{array}{c}12.8 \pm 2.78 \\
10.5-18.5\end{array}$ & $\begin{array}{c}15 \pm 18.8 \\
<10\end{array}$ & -0.175 & NS \\
\hline
\end{tabular}

NS - not statistically significant. 
Table II Serum zinc and CRP results (mean \pm s.d.) in two series of acute geriatric patients, subdivided according to their CRP levels

\begin{tabular}{lccccc}
\hline & Subgroup & $\begin{array}{c}C R P \\
m g / l\end{array}$ & $n$ & $\begin{array}{c}\text { Zinc } \mu \text { molll } \\
\text { Mean } \pm \text { s.d. }\end{array}$ & $\begin{array}{c}\text { CRP mg/l } \\
\text { Mean } \pm \text { s.d. }\end{array}$ \\
\hline 1st series & A & $<10$ & 39 & $11.3 \pm 2.24$ & $<10.0$ \\
$(n=103)$ & B & $11-50$ & 42 & $10.5 \pm 2.51 \mathrm{NS}$ & $23 \pm 10.7$ \\
& C & $51-100$ & 13 & $11.4 \pm 3.46 \mathrm{NS}$ & $69 \pm 12.7$ \\
& D & $>100$ & 9 & $7.8 \pm 3.72^{* * *}$ & $143 \pm 13.3$ \\
2nd series & A & $<10$ & 52 & $12.7 \pm 2.86$ & $<10.0$ \\
$(n=135)$ & B & $11-50$ & 33 & $12.2 \pm 2.61^{*} \mathrm{NS}$ & $29 \pm 10.6$ \\
& C & $51-100$ & 29 & $11.2 \pm 2.69^{*}$ & $77 \pm 13.9$ \\
& D & $>100$ & 21 & $10.4 \pm 3.71^{* *}$ & $137 \pm 43.5$ \\
\hline
\end{tabular}

Statistical difference between serum zinc results in subgroup A compared with subgroups $\mathrm{B}, \mathrm{C} \& \mathrm{D}$ respectively: ${ }^{* *} P<0.001 ;{ }^{* *} P<0.01$; ${ }^{*} P<0.05$; NS not significant.
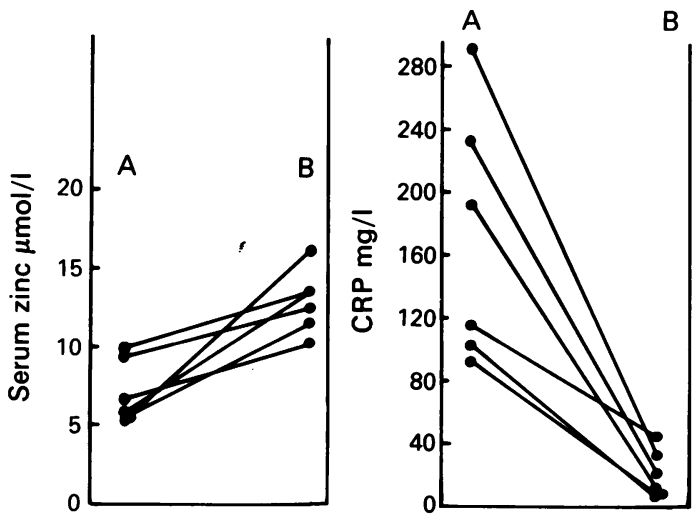

Figure 2 Sequential changes in zinc and CRP in 6 patients with bacterial infections. $A=$ results during acute phase; $B=$ results after recovery. Note rise in serum zinc and fall in CRP with treatment and recovery.

acute infections ${ }^{7,8}$ and tissue injury ${ }^{9}$ as a result of acute influx of zinc into the liver. This is probably caused by interleukin I, a chemical mediator released from activated macrophages.$^{10}$ This hepatic uptake of zinc is associated with synthesis of alpha-2-acute phase reactant proteins ${ }^{4,5}$ such as CRP. However, a negative correlation between serum zinc and CRP has not been previously reported.

CRP measurement may be of clinical value in distinguishing patients with true zinc deficiency from those with a low serum zinc due to the acute zinc redistribution of an acute phase response. This distinction may be important since zinc supplements are likely to be beneficial in zinc deficiency ${ }^{11}$ but could theoretically be harmful if given during an acute phase response. A low serum zinc should alert the clinician to the possibility of a severe infection, and this should be excluded before zinc supplements are given. We advise caution in the use of zinc supplements in patients with infection because there is evidence that zinc can impair granulocyte and $\mathrm{T}$ cell function. ${ }^{12}$

Most of our patients with a low serum zinc and a high CRP had evidence of a severe bacterial infection. An exception to this rule was a patient with high CRP associated with a hypernephroma and an active gastric ulcer. In an acute phase response the serum zinc and CRP levels return to normal spontaneously with recovery. Many of the patients with a low serum zinc and a normal CRP were candidates for true zinc deficiency since they lived alone, in poor social circumstances, ate little and were often on diuretic therapy.

A fall in serum zinc has beneficial effects on $T$ lymphocytes and polymorphonuclear leucocyte function in vitro ${ }^{13}$ and in vivo in animals. ${ }^{14}$ It is therefore quite possible that the acute phase fall in serum zinc in man has some beneficial effects and may enhance polymorphonuclear leucocyte and $T$ lymphocyte function. The evidence relating to the effect of zinc on polymorphonuclear leucocyte function is, however, conflicting. When apparently healthy men are given $150 \mathrm{mg}$ of elemental zinc twice daily for 6 weeks there is a progressive reduction in polymorphonuclear leucocyte chemotactic migration, phagocytic ability and bactericidal capacity, and polymorphonuclear leucocyte function remains suppressed for up to 10 weeks after cessation of zinc supplements. ${ }^{12}$ On the other hand abnormal granulocyte chemotaxis in acrodermatitis enteropathica is corrected by zinc therapy ${ }^{15}$ and granulocyte motility improves as plasma zinc and granulocyte zinc levels rise in haemodialysis patients. ${ }^{16}$ This suggests that where there is true zinc deficiency zinc supplements can improve granulocyte function, but if given unnecessarily or in excess, zinc can impair granulocyte function. 
Similar conclusions can be drawn regarding the effect of zinc on lymphocyte function. In zinc deficient mice $T$ cell function is impaired. ${ }^{17-19}$ In men, zinc supplements cause an initial rise in the $T$ lymphocyte stimulation response to phytohaemagglutinin as mean plasma zinc levels rise from 8.3 to $10.1 \mathrm{mg} / \mathrm{l}$, but thereafter the $\mathrm{T}$ lymphocyte response decreases progressively as serum zinc levels rise above $18.1 \mathrm{mg} / \mathrm{l}^{12}$ In haemodialysis patients zinc supplements do not affect the lymphocyte response to phytohaemagglutinin and other mitogens ${ }^{16}$ and monocyte production of interleukin II is defective. $^{20}$

We suggest that CRP should be measured routinely if serum zinc levels are found to be low. If the
CRP is significantly raised we advise that zinc supplements should be avoided and a source of infection should be sought. If the clinical situation is suggestive of true zinc deficiency and the CRP is normal zinc supplements can be given. However, caution should be taken when interpreting zinc and CRP results in patients with defective monocyte function and this area deserves further study.

\section{Acknowledgements}

We thank our consultant colleagues, in particular Drs $R$ Sutcliffe, B. Morgan and R. Morgan for allowing us to study patients under their care.

\section{References}

1. Craig, G.M., Evans, S.J., Brayshaw, B.J. \& Raina, S.K. A study of serum zinc, albumin, alpha-2-macroglobulin and transferrin levels in acute and long stay elderly hospital patients. Postgrad Med J 1990, 66: 205-209.

2. Stuart, J. \& Lewis, S.M. Monitoring the acute phase response (Editorial). Br Med J 1988, 297: 1143-1144.

3. Cox, M.L., Rudd, A.G., Gallimore, R., Hodkinson, H.M. \& Pepys, M.S. Real-time measurement of serum C-reactive protein in the management of infection in the elderly. Age Ageing 1986, 15: 257-266

4. Powanda, M.C. Changes in body balance of nitrogen and other key nutrients - description and underlying mechanics. Am J Clin Nutr 1977, 30: 1254-1268.

5. Prasad, A.S. Clinical endocrinological and biochemical effects of zinc deficiency. Clin Endocrinol Metab 1985, 14: $567-589$.

6. Lindeman, R.D. \& Mills, B.J. Zinc homeostasis in health and disease. Mineral Electrolyte Metab 1980, 3: 223-236.

7. Vikbladh, I. Studies on zinc in blood. Scand J Clin Lab Invest 1951, 3 (Suppl. 2): 1-72.

8. Beisel, W.R. Zinc metabolism in infection: In: Brewer, G.J. and Prasad, A.S. Zinc Metabolism. Current Aspect in Health and Disease. Liss, New York, 1977, pp. 155-176.

9. Lindeman, R.D., Bottomley, R.G., Cornelison, R.L. \& Jacobs, L.A. Influence of acute tissue injury on zinc metabolism in men. J Lab Clin Med 1972, 79: 452-460.

10. Dinarello, C.A. An update on human Interleukin I: from molecular biology to clinical relevance. J Clin Immunol 1985 , 5: $287-297$.

11. Winchurch, R. Zinc metabolism and immune ageing. In: Goidl, E. (ed.) Ageing and the Immune Response. Marcel Dekker Inc, New York and Basle, 1987, pp. 295-308.
12. Chandra, R.K. Excessive intake of zinc impairs immune responses. JAMA 1984, 252: 1443-1446.

13. Chvapil, M. Effect of zinc on cells and biomembranes. Med Clin North Am 1976, 60: 799-812.

14. Yatsuyanagi, J., Iwai, K. \& Ogiso, T. Suppressive effect of zinc on some functions of neutrophils: studies with carrageenan-induced inflammation in rats. Chem Pharm Bull 1987, 35: 699-704.

15. Weston, W.L., Huff, J.C., Humbert, J.R., Hambridge, K.M., Neldner, K.H. \& Walravens, P.A. Zinc correction of defective chemotaxis in acrodermatitis enteropathica. Arch Dermatol 1977, 113: 422-425.

16. Briggs, W.A., Pederson, M.M., Mahajan, S.K., Sillix, D.M., Prasad, A.S. \& McDonald, F.D. Lymphocyte and granulo-? cyte function in zinc-treated and zinc deficient haemodialysis patients. Kidney Int 1982, 21: 827-832.

17. Carlomagno, M.A. \& McMurray, D.N. Chronic zinc deficiency in rats: its influence on some parameters of humoral and cell-mediated immunity. Nutr Res 1983, 3: 69-77.

18. Fernandes, G., Nair, M., Onoe, K., Tanaka, T., Floyd, R. \& Good, R.A. Impairment of cell mediated immunity functions by dietary zinc deficiency in mice. Proc Natl Acad Sci USA 1979, 76: 457-461

19. Frost, P., Rabbani, P., Smith, J. \& Prasad, A. Cell-mediated cytotoxicity and tumor growth in zinc deficient mice. Proc Soc Exp Biol Med 1981, 167: 333-337.

20. Meuer, S.C., Dumann, H., Meyer zum Buschenfelde, K.H.M. \& Kohler, H. Low-dose interleukin-2 induces systemic immune responses against $\mathrm{HBsAg}$ in immunodeficient nonresponders to hepatitis B vaccination. Lancet 1989, i: 15-17. 